\title{
Politique
}

\section{Répertoire des thèses en science politique}

Volume 1, numéro 2, automne 1982

Les médias et les pouvoirs

URI : https://id.erudit.org/iderudit/040415ar

DOI : https://doi.org/10.7202/040415ar

Aller au sommaire du numéro

Éditeur(s)

Société québécoise de science politique

ISSN

0711-608X (numérique)

Découvrir la revue

Citer ce document

(1982). Répertoire des thèses en science politique. Politique, 1(2), 201-204.

https://doi.org/10.7202/040415ar

Ce document est protégé par la loi sur le droit d'auteur. L'utilisation des services d'Érudit (y compris la reproduction) est assujettie à sa politique d'utilisation que vous pouvez consulter en ligne.

https://apropos.erudit.org/fr/usagers/politique-dutilisation/
Cet article est diffusé et préservé par Érudit.

Érudit est un consortium interuniversitaire sans but lucratif composé de l’Université de Montréal, l'Université Laval et l'Université du Québec à Montréal. Il a pour mission la promotion et la valorisation de la recherche. https://www.erudit.org/fr/ 
Répertoire de thèses en science politique soutenues

à l'Université d'Ottawa et à l'Université du Québec à Montréal (1979-1981)*

NOM

Allaire, Benoit G Beaulne, Léonard

Gervais, Gylliane

Houda, Fatima

Lamont, Michèle

Maheux, Serge

Spillane, Nicholas J.

Browne, Paul

Francis, Théo B.

Gagnon, Richard Larochelle, Marc

\section{TITRE}

Les enjeux de la question linguistique au Québec.

Les fondements de la théorie politique chez Jürgen Habermas

L'État capitaliste face aux disparités régionales

Le transfert de technologie et la dépendance des pays du Tiers-Monde: cas des systèmes internationaux d'information

La conception de la connaissance et ses rapports avec la conscience de classe du problétariat chez Lenine - une critique

Analyse politique de la planification urbaine dans l'Outaouais québécois

An Uncertain Step - The law reform commission of Canada and the legislative process

Idéologie et pratique théorique: essai sur l'antihumanisme théorique de Louis Althusser

La Communauté économique des États de l'Afrique de l'Ouest (CEDEAO): une analyse de l'intégration régionale en Afrique noire.

Le Québec dans le monde

L'intégration régionale, l'internationalisation du capital, et la programmation sectorielle: une étude comparative des expériences de l'association des nations de l'Asie du sud-est (Anase) et du groupe Andin

\section{DIPLÔME \& ANNÉE UNIVERSITÉ}

M.A., 1979
M.A., 1979
M.A., 1979
M.A., 1979

M.A., 1979

M.A., 1979

M.A., 1979

M.A., 1980

M.A., 1980

M.A., 1980

M.A., 1980
Université d'Ottawa

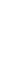


Légaré, Claude

Perron, Bruno

Rivard, Jocelyne

Antinori, Alain

Bertrand, Jacques

Carignan, Daniel

Gagnon, Réal

Levasseur, Danielle

Macalou, Demba

Bélanger, Yves

Boucher, Pierre

Bullick, Lucie

Chagnon, Yves
La politique urbaine et le rôle de l'État: étude de cas

La loi de la valeur chez Christian Palloix

La notion du parti chez Antonio Gramsci

Le problème de l'État dans la pensée de Karl Marx et de Samir Amin

L'Union des municipalités du Québec: une analyse de ses relations avec le gouvernement provincial de 1960-1980

Les effets en aval du système électoral québécois - 1970-1976

Les effets de la pénétration des multinationales sur le développement des pays Latino-Américains

Le grand tournant de la politique étrangère Chinoise: le rapprochement de la Chine avec les États-Unis 1971 1- 1972

Politique d'éducation et développement économique et social au Mali

Bourgeoisie et fractions de classe dans l'industrie québécoise de la construction

La conception théorico-politique de l'hégémonie chez Gramsci

Militarisme, crises du système de domination et luttes de classes au Pérou, 1821-1968

La loi sur la protection du territoire agricole: les enjeux et les conditions de succès d'une réforme majeure
M.A., 1980

M.A., 1980

M.A., 1980

M.A., 1981

M.A., 198

M.A., 1981

M.A., 1981

M.A., 1981

M.A., 1981

M.A., 1980

M.A., 1980

M.A., 1980

M.A., 1981

\section{Université d'Ottawa}

"

Un. du Québec à Montréal

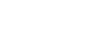


Cyr, François

et

Roy, Rémi

Desbiens, Nicole

Duquette, Michel

El Helou, Antoine

Enriguez, Carlos

Fezzani, Mohamed

Gervais, Myriam

Giguère, André

Legada-Leounda, Julien

Marleau, René

Mataigne, Bernard

Plasse, Micheline

Poirier, Louise

Séguin, François
La fédération des travailleurs du Québec et la question nationale de 1955 à 1976

Éléments pour l'analyse politique de la branche Pâtes et Papiers au Québec

Le Portugal: Une expérience de réforme agraire

La crise de l'État libanais (1975-77)

La diplomatie de la dépendance: le nouvel ordre économique international et la charte des droits et devoirs économiques des États

L'étude d'un cas de dépendance nord-sud: les relations Tunisie-CEE: problèmes actuels et perspectives futures

Les transformations des rapports sociaux de production dans la région sahelienne

Écologie politique du secteur forestier au Québec Les institutions politiques traditionnelles OBAMBA (Du Gabon) face au fait colonial

L'idéologie des groupes de pression néo-québécois dans leur opposition au projet de loi no 101

Le mouvement socialiste au Québec 1965-1970

Les chefs de cabinets ministériels au Québec

Le mode de fonctionnement bureaucratique dans l'administration de la Ville de Montréal, 1978-1981

La tactique du front uni antifasciste et la politique du Parti communiste du Canada (19391945)
M.A., 1980

M.A., 1980

M.A., 1979

M.A., 1980

M.A., 1980

M.A., 1981

M.A., 1981

M.A., 1981

M.A., 1981

M.A., 1981

M.A., 1980

M.A., 1979

M.A., 1981

M.A., 1979
"

Un. du Québec à Montréal

,

$"$

" 
Shuleka, Edwidge

Thales, Max-Raymond

Vézina, Gilles

Desbiens, Nicole

Godin, Francine

Lépine, Jean-François

Mvilongo-Tsala, Anselme

Toupin, Louis
Atticudes de l'URSS envees la guecre au Vietnam entre 1954-1974

Cuba: «La révolution incomprise» ou la radicalisation conjoncturelle (1959-1962)

Analyse politique de la C.E.Q.

Éléments pour l'analyse politique de la branche Pâtes et Papiers au Québec

La crise de l'État au Dahomey (République populaire du Bénin) 1960-1972: Genèse et fondement

Les promoteurs du projet de cartonnerie populaire de Cabano

Dépendance et reproduction de la dépendance dans la politique étrangère du Cameroun. Un essai d'interprétation

Le militantisme syndical à la C.E.Q. face à la qualité de l'enseignement (1978)
M.A., 1979

M.A., 1980

M.A., 1981

M.A., 1980

M.A., 1981

M.A., 1979

M.A., 1981

M.A., 1980
$"$

"

* La liste des thèses soutenues dans les autres universités québécoises a été publiée dans le numéro 1 de POLITIQUE. 